\title{
THORACOPLASTY WITH PLOMBAGE: A REVIEW OF THE EARLY RESULTS IN 125 CASES
}

\author{
BY \\ B. G. B. LUCAS AND W. P. CLELAND \\ London
}

Cavity closure and sputum conversion by the modern thoracoplasty with apicolysis occurs in the majority of cases (Price and Cleland, 1943 ; Sellors, 1947), but the operation entails a moderate risk of atelectasis and spread of tuberculous disease and can only be performed safely in stages because of the untoward effects of paradoxical movements of the chest wall and lung which follow excessive resection of ribs. The psychological effect of a multiple stage operation is undoubtedly harmful, and the resultant physical deformity, particularly that of a total thoracoplasty, is often a source of concern both to patient and physician.

The indications for thoracoplasty as originally outlined by Sauerbruch (1920) have been extended as the operation itself has been modified in the light of experience, but there remains a group of patients in whom the risks of surgical intervention become prohibitive. Extrapleural pneumolysis, first performed by Tuffier (1891) was revived by Brock (1938), J. E. H. Roberts (1938), and Sellors (1938) independently as an alternative procedure for this poor risk group. The advantages were a single stage operation with retention of an intact chest wall. The operation carried a lower post-operative pulmonary morbidity but introduced complications relevant to the maintenance of a dead space in the body. A. T. M. Roberts (1948) reviewing 128 cases of extrapleural pneumolysis reported an incidence of approximately $16 \%$ of tuberculous space infections, and haemorrhage into the space has been recorded as a complication in $5 \%$ to $20 \%$ (Cleland, 1948). To eliminate this dead space and at the same time to maintain the collapse, a variety of substances have been used to fill the space but all have proved unsatisfactory, chiefly because of the irritation they produce. The introduction of air has been the most satisfactory method, but this merely maintains the collapse without eliminating the dead space.

The recent introduction of plastics into surgery (Kleinschmidt, 1941) as a nonirritant material has been followed by experimental work on the use of these materials for extrapleural plombage. Wilson (1948) first reported 15 cases in which several hollow spheres of polymethyl methacrylate (" perspex") were successfully employed to fill the dead space. Subsequent reports (Trent, Moody, Hiatt, and McCain, 1949 ; Walkup and Murphy, 1949) record a high incidence of complications with this method. Pyogenic and tuberculous space infections; migration of the spheres into the neck, mediastinum, and subcutaneous tissues; ulceration into the lung; and pressure phenomena have all occurred frequently. Detailed analysis of these reports suggest that this high complication rate may have been due to some of the following factors : 


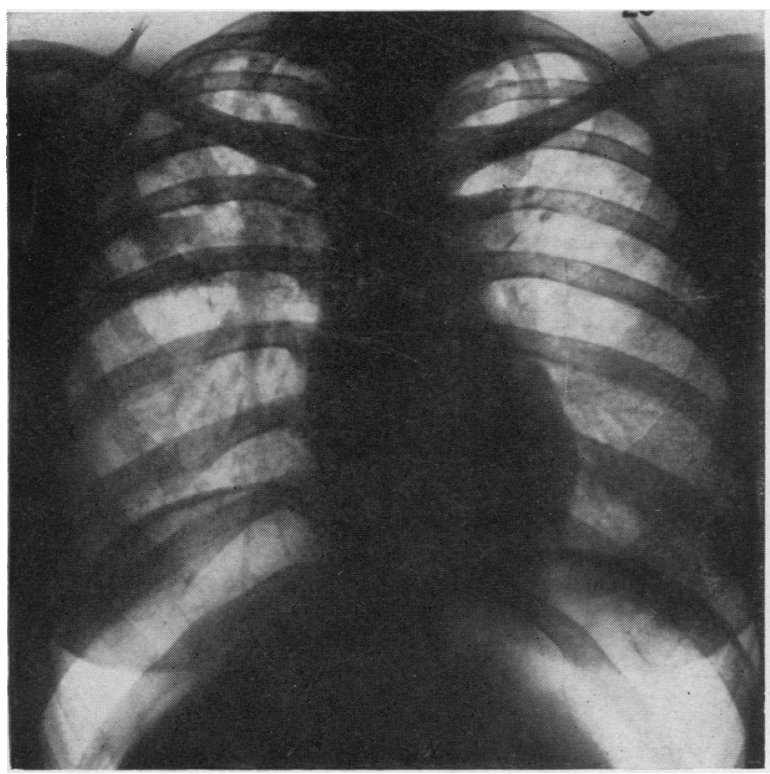

Fig. $1 a$.

FIG. 1 (a).-Pre-operative radiograph of a woman of 25 years with a moderate sized sub-apical cavity on the right side and scattered infiltration on the left, on whom a 7-rib "bird cage" operation was performed using hollow spheres.

FIGs. $1(b)$ and $1(c)$.-Postero-anterior and lateral films six months after operation to show extent and sciective nature of the collapse.

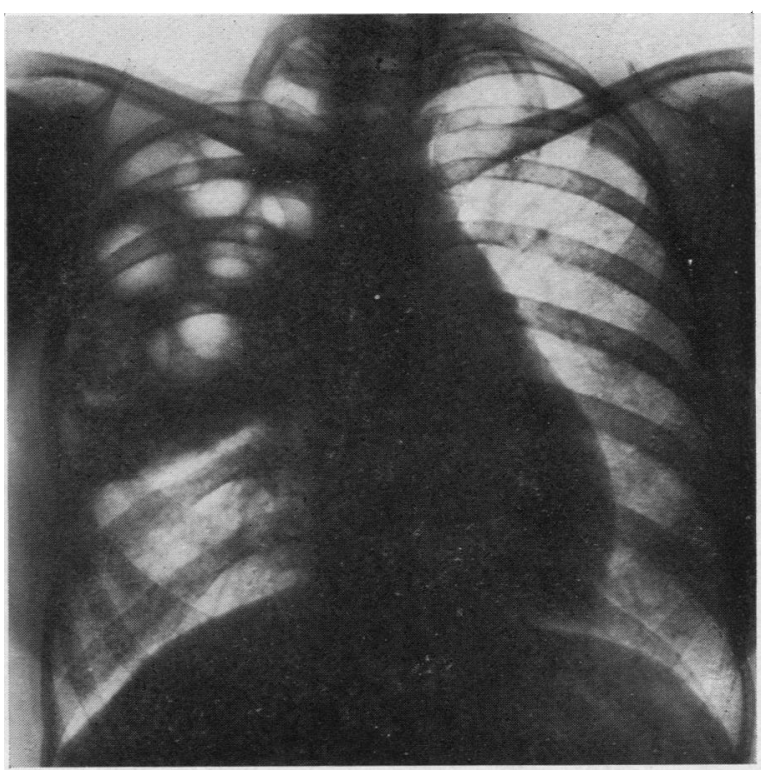

Fig. $1 b$.

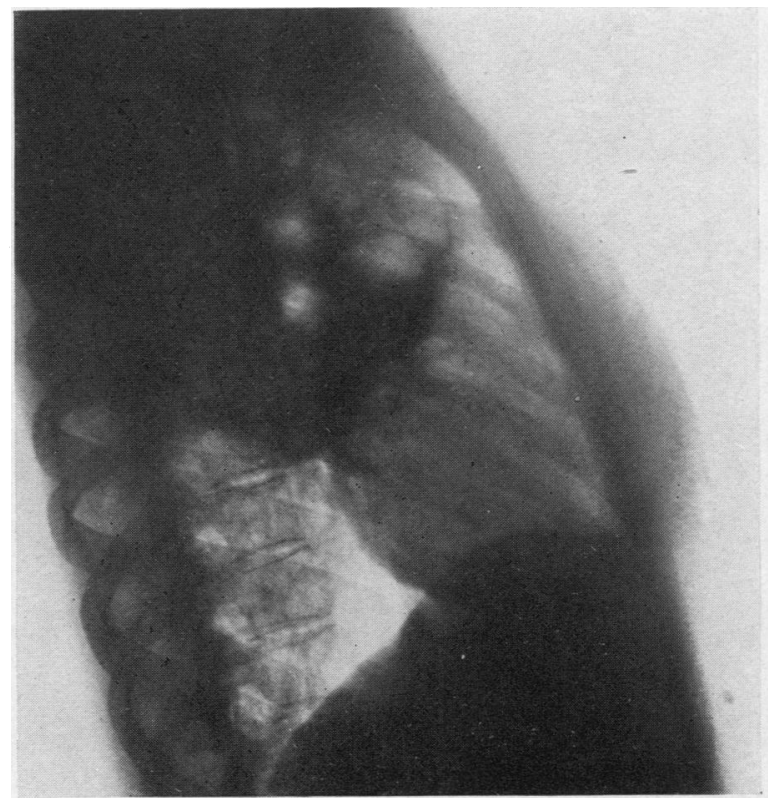

Fig. 1c. 
(1) Plombage has been used with extrapleural pneumolysis, and the incidence of tuberculous space infections with this method (21.5\%, Trent and others, 1949) and those in extrapleural pneumothorax $(16 \%$, Roberts, 1948) is sufficiently close to suggest that the plastic material is not the causative agent. (2) Many of the patients were unsuitable for any form of collapse therapy. (3) In most cases the space appeared to be overfilled with spheres causing tension on the surrounding tissues. (4) The plastic material may have been rendered irritant by the use of varying plasticizers in its manufacture.

To overcome the deficiencies of the modern thoracoplasty and at the same time to embody the advantages of plombage, an operation has been devised which is primarily an ordinary thoracoplasty in which the relaxation of the lung is maintained by the insertion of plastic spheres.

Two plastic materials have been used, polymethyl methacrylate ("perspex," "lucite") and polyethylene ("alkathene," "polythene"). Experimentally both these substances are relatively non-irritant if manufactured without the use of plasticizers. Hollow "perspex" spheres were used of a similar pattern to those described by Wilson (1948). These are light in weight but preparation is tedious and sterilization difficult. To overcome this latter disadvantage, solid "polythene" spheres, one inch in diameter, have been used. These, although heavier, can be sterilized by boiling.

This report is based on 125 cases operated upon between August, 1948, and February, 1950, in which this procedure has been employed. In the early cases hollow "perspex" spheres were alone available (Fig. $1 a, b, c)$; later solid "polythene" ones were used (Fig. $2 a, b$ ). There was no significant difference between the groups.

\section{INDICATIONS FOR OPERATION}

Initially cases suitable for standard thoracoplasty were selected. Later cases included those which would normally have been considered unsuitable for thoracoplasty because of the extent or activity of the disease, age or coincidental emphysema and chronic bronchitis. The majority of the poor risk cases came into this latter category (Table I).

TABLE I

ANALYSIS OF CASES

\begin{tabular}{|c|c|c|c|c|c|}
\hline \multicolumn{3}{|c|}{ Type of Case } & No. & Atelectasis & Spread \\
\hline $\begin{array}{l}\text { Good risk } \\
\text { Fair risk } \\
\text { Poor risk }\end{array}$ & $\begin{array}{ll}. & . \\
\cdots & \cdots \\
. & . .\end{array}$ & $\begin{array}{l}. \\
\ldots \\
.\end{array}$ & $\begin{array}{l}72 \\
36 \\
17\end{array}$ & $\begin{array}{l}3 \\
2 \\
0\end{array}$ & $\begin{array}{l}4 \\
1 \\
0\end{array}$ \\
\hline \multicolumn{2}{|r|}{ Total } & .. & 125 & $5(4 \%)$ & $5(4 \%)$ \\
\hline \multicolumn{2}{|c|}{ Other thoracoplasty } & .. & 240 & $22(9 \%)$ & $24(10 \%)$ \\
\hline
\end{tabular}

\section{Operative Procedure}

The hollow "perspex" spheres were manufactured in two halves which were sterilized chemically by immersion for 48 hours in phenyl mercuric nitrate or 
"cetavlon." The two halves were cemented together under sterile conditions and then replaced in the original antiseptic solution and were ready for use in a further 48 hours. The solid "polythene" spheres were sterilized by boiling.

In the majority of cases a permanent plomb has been used, and in only 11 cases was it employed between the stages of a thoracoplasty as a temporary measure. The earlier permanent plombs were used in cases with limited apical disease after mobilization approximating that of a first stage thoracoplasty with apicolysis (Fig. $3 a-d$ ). The results were satisfactory and cavity closure and sputum conversion occurred in the majority. Cases with more extensive disease and larger cavities were then submitted to this operation but it was found that on several occasions horizontal slit-like cavities persisted. This suggested that additional lateral and posterior mobilization was required to produce a more concentric type of relaxation. Consequently, in the later cases lateral mobilization of the lung

Pre- and post-operative radiographs of a woman of 22 on whom a 6-rib "bird cage" operation was performed using solid "polythene" spheres.

FIG. 2 (a) shows bilateral upper zone cavities more extensive on the left.

FIG. $2(b)$.- Six weeks after operation with a moderate effusion still present; further contraction is to be expected. The opposite lung has already improved.

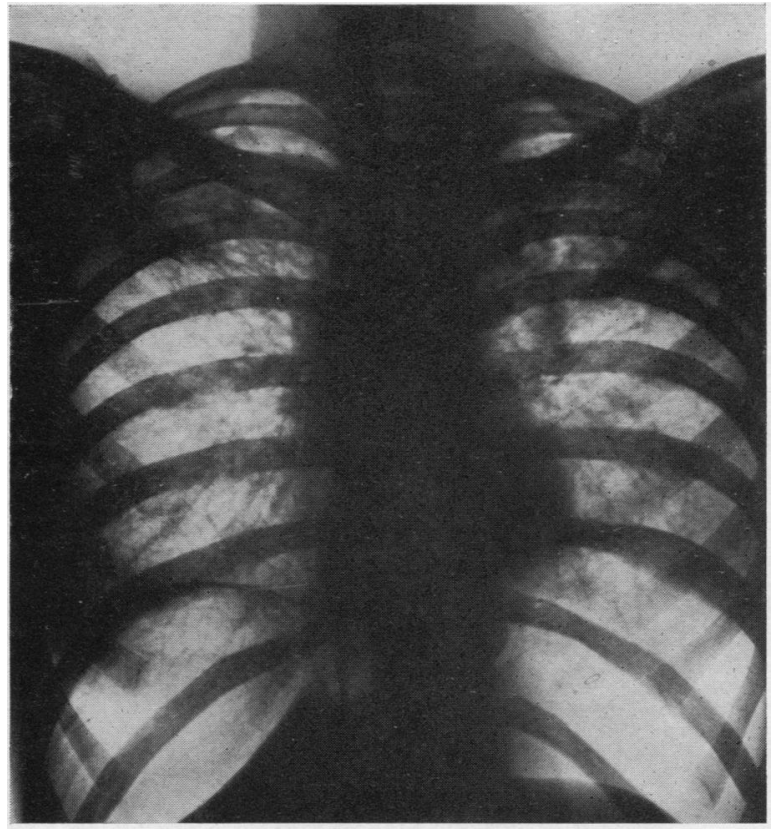

FIG. $2 a$.

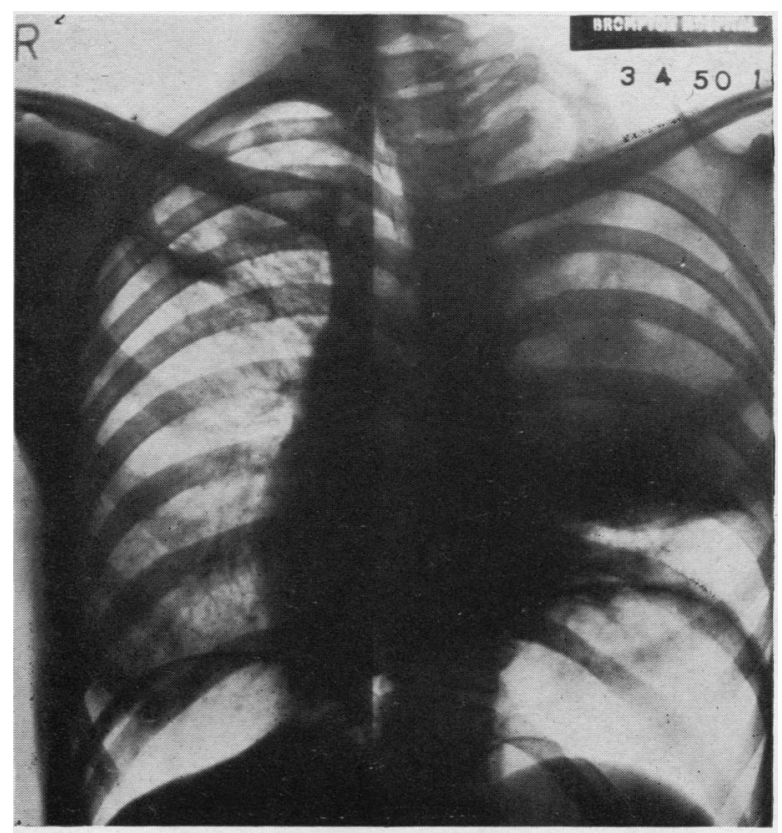

FIG. $2 b$. 


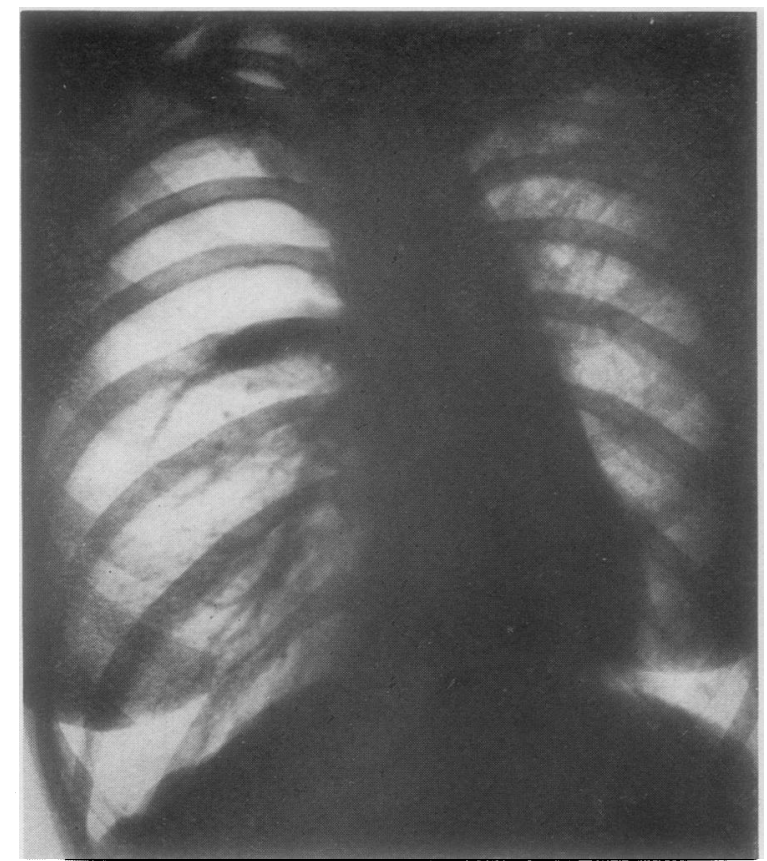

FIG. $3 a$

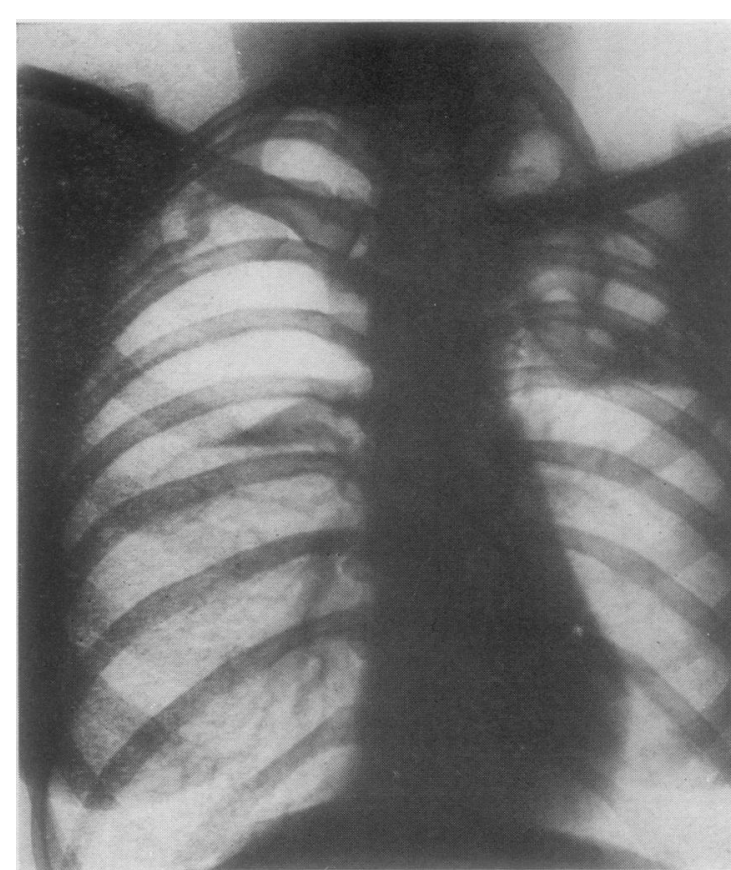

FIG. $3 b$

FIG. 3 (a).-Pre-operative film of chest of a woman of 30 years with a large cavity at the left apex and a contralateral extrapleural pneumothorax. Apical plomb was performed using hollow balls. Fig. $3(b)$.- Radiograph taken 11 months after operation.

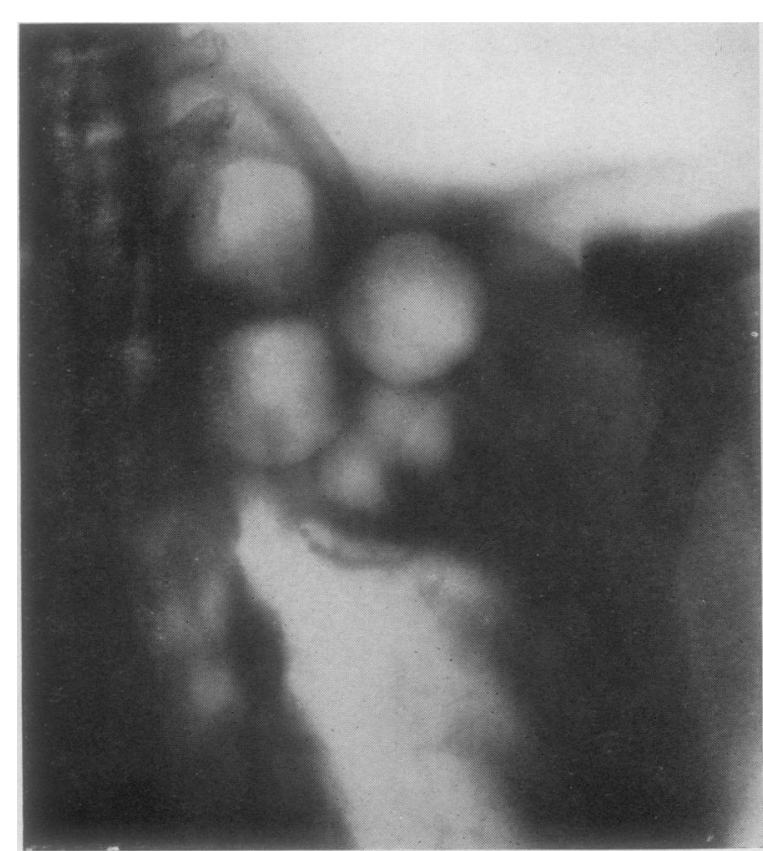

FIG. $3 c$

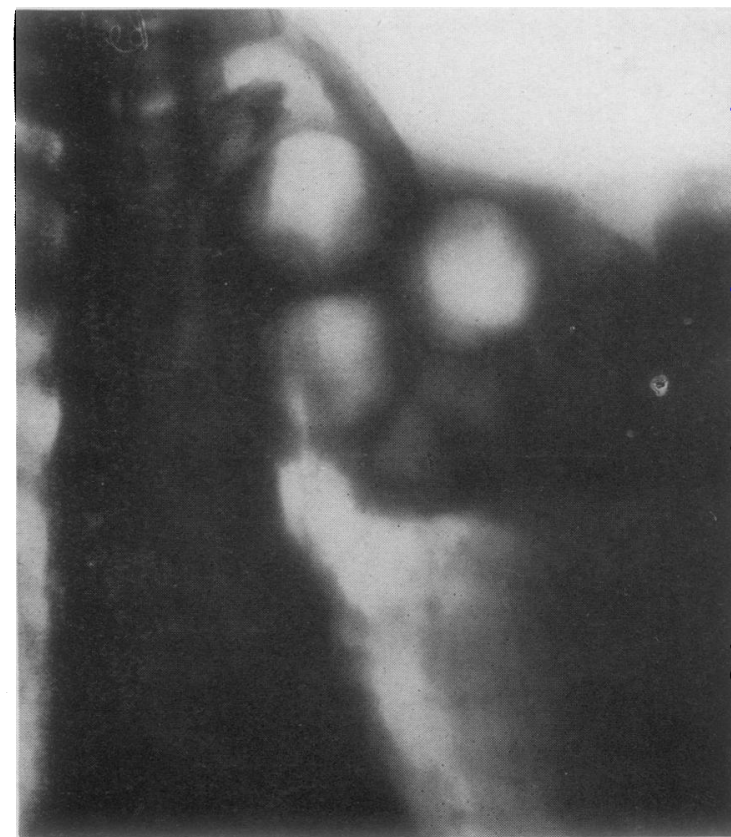

Fig. 3d

Figs. $3(c)$ and $3(d)$.-Tomographs $(6 \mathrm{~cm}$.) three and nine months after operation respectively. Fig. $3(c)$ shows a small horizontal cavity below the plomb, whereas Fig. $3(d)$ shows no evidence of its persistence. 
from the chest wall and the costo-vertebral gutter was added to the apicolysis, of sufficient degree to extend just below the diseased area as determined radiographically. There is no limit to the degree of mobilization undertaken, and in many cases it has been extended as far as the eighth or ninth ribs without ill efiect.

The present operative technique entails removing approximately half of the third rib and the greater part of the second rib. This gives adequate access to the apex and mediastinal aspect of the lung and permits accurate dissection and mobilization under direct vision. The periosteum is stripped from the under surface of the first rib but the rib itself is not removed. Mobilization is carried down on the mediastinal aspect, if necessary to the aortic arch or azygos vein. Lateral and posterior mobilization is effected by incising the periosteum along the upper and lower borders of the desired number of ribs and stripping it from the deep surfaces. The intercostal muscles and bundles are divided posteriorly and remain attached to the mobilized lung leaving the denuded ribs. The appearance after mobilization is often referred to as the "bird cage" (Figs. 1, 2, and 4). The plastic spheres are loosely packed into the space. The scapula and its muscles effectively keep the balls in place and in no case have they migrated from the space.

Of the 125 cases, 64 had the more limited apical plombage and 50 the more extensive procedure with postero-lateral

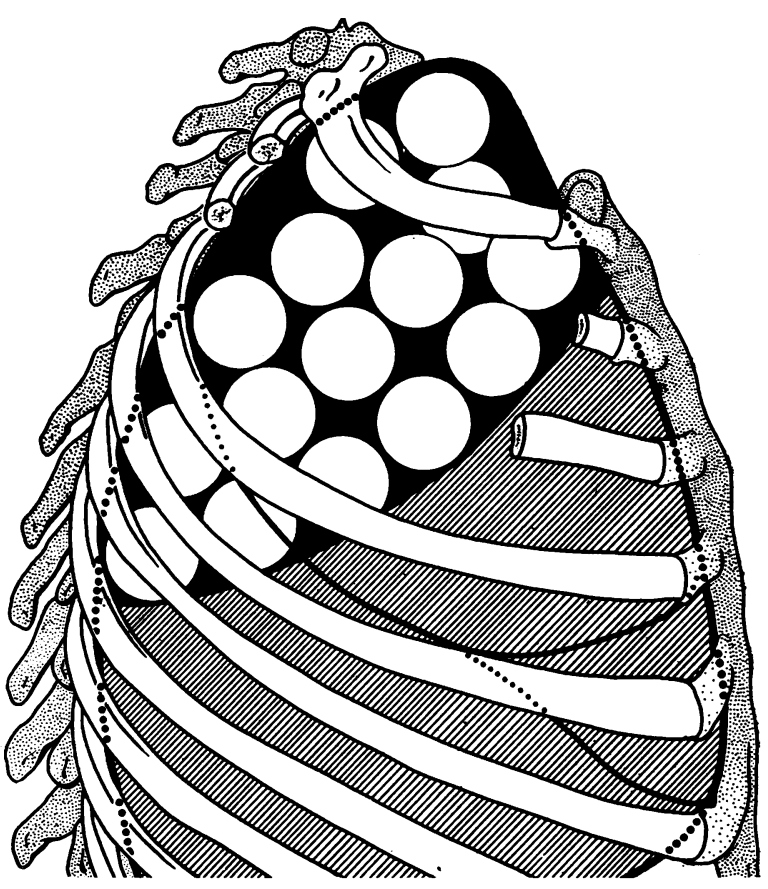

APICO-POSTERIOR PLOMBAGE

FIG. 4 mobilization extending as far as the fifth to the ninth rib according to the extent of the lesion. Mobilization was normally carried as far down as one rib below the cavitated or grossly diseased area, although recently less extensive mobilization has been carried out because post-operation radiographs have shown that the collapse has been well maintained without any upward migration of the lung. The former group of apical plombs includes mainly cases which would normally have been treated by a limited three or four rib thoracoplasty, but early in this series some of the more extensive lesions were successfully treated by apical plombage alone before the "bird cage" operation was developed. 
TABLE II

ANALYSIS OF COMPLications IN 125 CASES

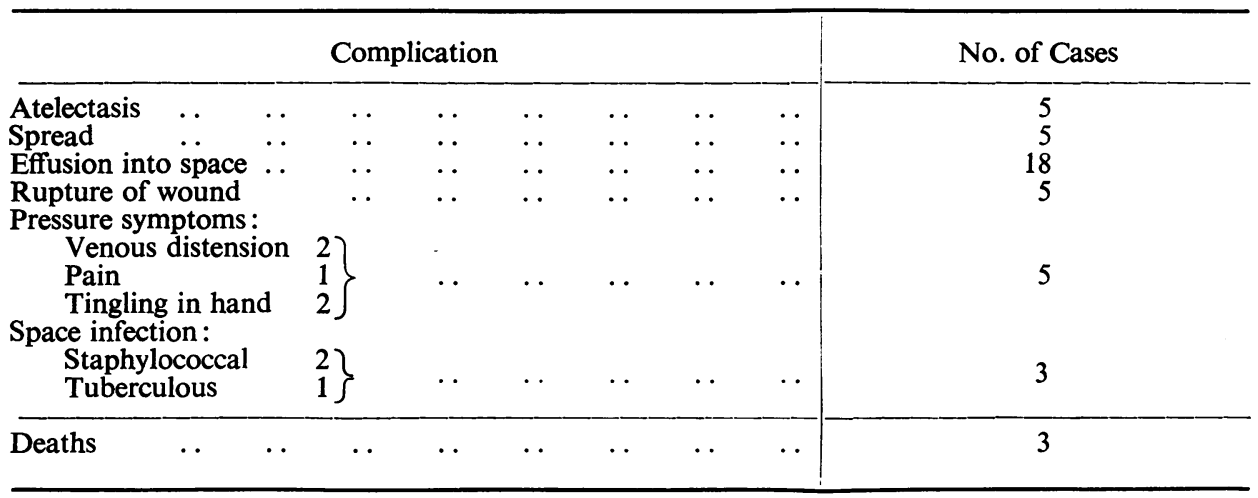

\section{Complications}

Table II shows the complications in the whole group. Serosanguineous effusion requiring one or more aspirations occurred in 18 cases, the majority of these (14) being with the more extensive apico-posterior plombage. The dead space following apicolysis is almost completely occupied by the plomb so that liquid which may collect cannot readily be accommodated and will either compress the lung further, giving rise to pressure symptoms, or will seep out into the muscle planes and may even precipitate wound rupture. These cases are now aspirated when liquid accumulates in order to prevent these sequelae.

Pressure symptoms, apart from those due to liquid, have occurred in five cases. In two the neck and arm veins were moderately distended for the first few days but rapidly subsided and two other patients complained of tingling in the fingers for two to three days. In only one case was there pain of any severity or duration ; the patient was a woman who had a contralateral pneumothorax and developed severe pain over the upper dorsal vertebrae after each refill. The pain was relieved when the space was reopened and smaller balls used to replace the larger ones originally inserted. Two staphylococcal and one tuberculous space infections occurred. The former appeared early and in one was controlled by aspirations and penicillin instillation. In the other it was secondary to a staphylococcal infection of the upper portion of the wound, and in this instance the balls were removed and a formal

TABLE III

TYPES OF OPERATION AND COMPLICATIONS

\begin{tabular}{|c|c|c|c|c|}
\hline Operation & No. & Effusion & Atelectasis & Spread \\
\hline $\begin{array}{l}\text { Between stages of Semb thoracoplasty ... } \\
\text { Apical plombage (mobilization: 1st stage) } \\
\text { Apico-posterior plombage (mobilization: } \\
5-8 \text { rib thoracoplasty) .. }\end{array}$ & $\begin{array}{l}11 \\
64 \\
50\end{array}$ & $\begin{array}{r}0 \\
4 \\
14\end{array}$ & $\begin{array}{l}0 \\
2 \\
3\end{array}$ & $\begin{array}{l}1 \\
2 \\
2\end{array}$ \\
\hline Total & 125 & 18 & 5 & 5 \\
\hline
\end{tabular}


seven rib thoracoplasty performed with control of the infection. The tuberculous space infection occurred six months after operation in a man who had an unrecognized cold abscess of the chest wall which was opened at the time of operation.

Atelectasis and spread of tuberculous disease are analysed in Tables I and III. Atelectasis was recorded when there was either clinical or radiological evidence of an airless base at any time. Definition of "spread" was where radiological changes persisted after the first seven days; it did not include minor variations in shadows seen in the early post-operation portable apparatus radiographs which were probably dependent on differences in technique.

In Table I the cases are classified into good, fair, or poor risks for thoracoplasty. There was no significant difference in the atelectasis and spread rates for the three groups. There were in all five cases of atelectasis and five of spread of disease either on the same or the opposite side in the series. By contrast there was just over double that number of each in a series of 240 thoracoplasties performed (W.P.C.) under similar conditions during the preceding three years.

Table III indicates that the more extensive apico-posterior plomb is attended by more frequent occurrence of effusions and a slight increase in the incidence of atelectasis. This is to be expected, as in the former case there is a greater raw area whilst in the latter the lung is more extensively involved and therefore more liable to become atelectatic after operation.

There have been three deaths in the series, but in no instance was this attributable to the use of plombage.

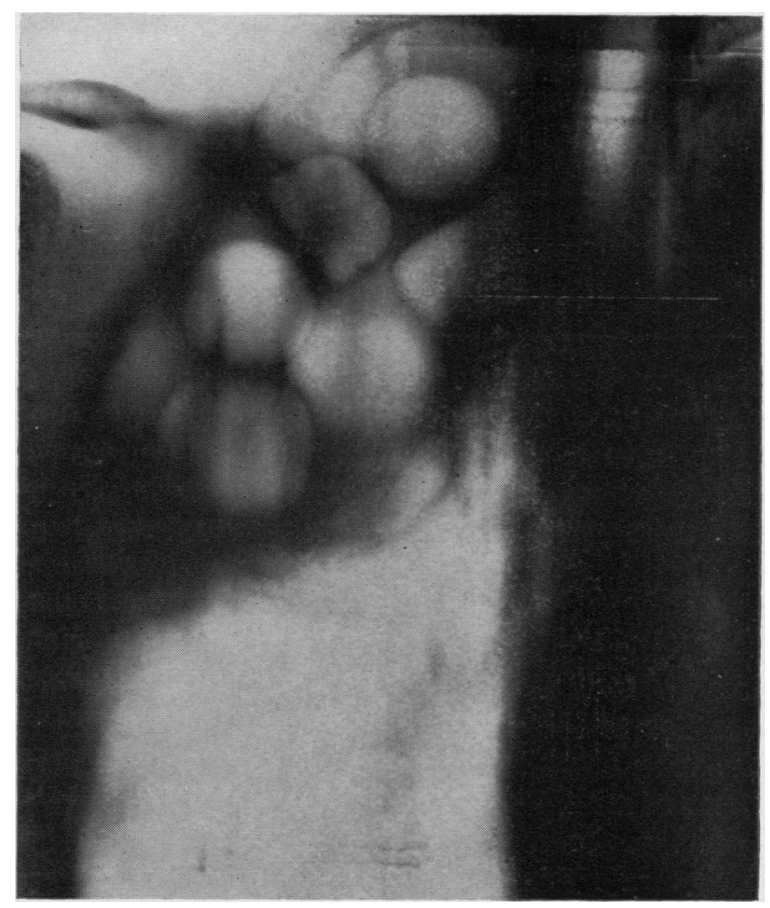

FIG. 5.-Tomograph $(10 \mathrm{~cm}$.) three months after plombage to show a residual cavity $2.5 \mathrm{~cm}$. $\times 0.8 \mathrm{~cm}$. below and medial to the plomb and readily distinguished from the latter.

\section{Discussion}

The post-operative condition of these patients has been good, due probably to the absence of paradoxical movement of the chest wall and lung. This has reduced disturbances of respiration to a minimum and has made coughing more effective. An impression has been gained that there is more post-operative discomfort than with an ordinary first stage thoracoplasty but that this is offset by its limited duration and the absence of subsequent stages. The physiotherapists have commented 
that rehabilitation in these patients is accomplished more quickly and easily. There is no final deformity.

A criticism of the use of plombage with hollow spheres has been the confusion which might arise between a residual cavity and a ball on tomography (Trent and others, 1949). In this series no such difficulty has arisen as regards radiological interpretation (Figs. 3 and 5); indeed it is easier and more satisfactory to read tomographs after plombage than after thoracoplasty, as there is not the same bizarre type of rib regeneration in these cases.

Difficulty has been experienced by other authors in removing the plastic balls at a later date (Trent and others, 1949). In this series they have been deliberately removed on 12 occasions. In eight they were removed within two to four weeks of insertion as part of a planned staged thoracoplasty and there was no evidence of any reaction. In four they were removed from seven to 11 months after insertion owing to the presence of persistent cavitation. In each case they were individually surrounded by a plaque of fibrin and the whole plomb was encased in relatively avascular fibrous tissue. In no instance was there excessive fibrous tissue formation nor was there any difficulty in removal.

\section{LATE RESULTS}

The future of plombage with plastic material will rest upon the incidence of late complications and upon the percentage of cavities closed and sputa converted. It is beyond the scope of this paper to discuss these questions, as sufficient time has not elapsed to evaluate the procedure from the long term point of view. However, there have been no late complications so far, and it seems probable that, after allowing for changes in operative technique, the results in terms of cavity closure and sputum conversion will approximate to those achieved with thoracoplasty.

\section{Conclusions and Summary}

Plastic plombage in conjunction with a modified thoracoplasty has been employed in a series of 125 cases. It is a procedure which does not carry any serious hazards peculiar to the plastic material. This operation reduces the incidence of some of the lung complications of thoracoplasty; it allows a safe one-stage procedure in place of multiple operations and reduces deformity of the thorax to a minimum. In addition, the added safety of the operation permits a widening of the indications for apicolysis to include many otherwise unsuitable cases.

Brock, R. C. (1938). Brit. J. Tuberc., 32, 173.

REFERENCES

Cleland, W. P. (1948). Thorax, 3, 127.

Kleinschmidt, O. (1941). Chirurg, 13, 714.

Price, Thomas C., and Cleland, W. P. (1943). Brit. J. Tuberc., 37, 2.

Roberts, A. T. M. (1948). Thorax, 3, 166.

Roberts, J. E. H. (1938). Brit. J. Tuberc., 32, 68.

Sauerbruch, F. (1920). Die Chirurgie der Brustorgane, vol. 1. Berlin.

Sellors, T. H. (1938). Brit. J. Tuberc., 32, 182.

- (1947). Thorax, 2, 216.

Trent, J. C., Moody, J. D., Hiatt, J. S., and McCain, N. C. (1949). J. thorac. Surg., $18,173$. Tuffier, T. (1891). Sem. méd., B. Aires, 11, 202.

Walkup, H. E., and Murphy, J. D. (1949). Dis. Chest., 16, 18.

-1 (1949). Ibid., 16, 456.

Wilson, D. A. (1948). J. thorac. Surg., 17, 111. 